\title{
Formulation, stability and analytical method validation of chasteberry (Vitex agnus-castus L.) extract in solid oral dosage forms
}

\author{
İlker DEMİRBOLAT 1,2* (D), Murat KARTAL 1 (i) \\ 1 Center of Education, Practice and Research in Phytotherapy, Bezmialem Vakıf University, 34093 Fatih, İstanbul, \\ Turkey. \\ 2 Department of Pharmaceutical Chemistry, Faculty of Pharmacy, Marmara University, 34668 Haydarpaşa, İstanbul, \\ Turkey. \\ * Corresponding Author. E-mail: idemirbolat@bezmialem.edu.tr (İ.D.); Tel: +90 216523 22 88-1881.
}

Received: 18 March 2019 / Revised: 15 April 2019 / Accepted: 25 April 2019

\begin{abstract}
Premenstrual syndrome (PMS) is a common condition that affects $90 \%$ of menstruating women on emotions, behaviours and physical health. Vitex agnus-castus L. also known as chasteberry or chaste tree is long being used for its health benefits on feminine problems like PMS and hyperprolactinemia. There are also some prescription medicines to ease the symptoms of PMS. While dietary supplements containing medicinal plants could be found everywhere with the lack of quality and standardisation, there are only a few registered traditional herbal medicinal products available on the market containing agnus-castus fruit extract. In this study we developed a stable film coated oral formulation and fully validated the analytical methods to quantify the extract in dosage forms to fulfil the requirements of CTD module 3 while registering the traditional herbal medicinal product according to European Union legislations.
\end{abstract}

KEYWORDS: Chasteberry; Vitex agnus-castus; validation; formulation; stability.

\section{INTRODUCTION}

Herbal remedies are widely used in the modern world as people believe that "herbal" means naturally "safe". Parallel to this increasing interest, companies produce huge amounts of dietary supplements with low quality raw materials and sometimes what's claimed on the label is lacked inside. Besides dietary supplements, traditional herbal medicinal products are regulated same way as the conventional medicines. Registration of herbal and conventional medicines requires application dossiers known as common technical document (CTD). The CTD consists of five modules and the third one contains all the required quality information and data about the product [1]. Module 3.2.S.4 has all the information for the active ingredient and 3.2.P.3.3 section of CTD describes the production steps of the product. 3.2.P.5.2 states the applied analytical procedures for drug products meanwhile 3.2.P.5.3 section covers all the analytical method validation data whether the product is herbal or conventional [2]. These registration requirements guarantees that the traditional herbal medicinal products are being manufactured with highest quality plant extracts and controlled in every steps of production.

Chasteberry tree or chaste tree (Vitex agnus-castus L.) -a member of Verbenaceae family-is a small shrub native to European, Mediterranean, and Central Asian countries. It has been long used traditionally for its medicinal properties indicated to female reproduction conditions like premenstrual problems and hyperprolactinemia [3, 6]. Dry extract of Vitex agnus-castus L. fruits also has a well-established use described in European Union herbal monograph with a daily dose of $20 \mathrm{mg}$ for female adults [7]. Derived information about marketed products containing Vitex agnus-castus L. in European Union signifies that most of the active ingredients are usually dry extracts with a posology of 4 to $20 \mathrm{mg}$ per day indicated to irregular menstruation, premenstrual syndrome and mastodynia. Also tinctures, liquid extracts and powdered herbal substances are being used for the same purposes with different posologies [8].

How to cite this article: Demirbolat I, Kartal M. Formulation, stability and analytical method validation of chasteberry (Vitex agnus-castus L.) extract in solid oral dosage forms. J Res Pharm. 2019; 23(4): 689-696. 
In European Pharmacopoeia (EP), agnus-castus fruit dry extract is standardised to a methoxylated flavonol called casticin -also known as vitexicarpin- not less than $0.1 \%$ in the extract [9]. Casticin was also reported for its anti-inflammatory, anti-malarial, anti-oxidant and anti-cancer activities [10-13]. There are several registered traditional herbal medicinal products in European Union containing agnus-castus fruit extract. In this study we developed a stable solid oral formulation and validated the assay method to evaluate the stability of products to comply CTD requirements.

\section{RESULTS AND DISCUSSION}

\subsection{Optimization of HPLC methods to quantify casticin in herbal extracts and tablets}

Various C18 columns were used to achieve the best separation and peak shapes to quantify casticin content of agnus-castus fruit extracts and herbal tablets. The column and mobile phase used in EP method [9] for determining casticin content of agnus-castus dry extract gives a resolution of 1.5 between penduletin and casticin so a different column was selected to achieve a better resolution. Method parameters were given in Table 1.

Table 1. Method parameters to quantify casticin.

\begin{tabular}{|c|c|c|}
\hline System & \multicolumn{2}{|c|}{ Shimadzu UFLC Prominence } \\
\hline Column & \multicolumn{2}{|c|}{ GLSciences ODS-3, $150 \mathrm{~mm} \times 4,6 \mathrm{~mm} \times 3 \mu \mathrm{m}$} \\
\hline Flow & \multicolumn{2}{|l|}{$1.0 \mathrm{~mL} / \mathrm{min}$} \\
\hline Detection & \multicolumn{2}{|l|}{$348 \mathrm{~nm}$} \\
\hline Enjection & \multicolumn{2}{|l|}{$20 \mu \mathrm{L}$} \\
\hline Column Oven & \multicolumn{2}{|l|}{$25^{\circ} \mathrm{C}$} \\
\hline Mobil Phase & \multicolumn{2}{|c|}{$\begin{array}{l}\text { Mobile Phase A: } 5.88 \mathrm{~g} / \mathrm{L} \mathrm{H}_{3} \mathrm{PO}_{4} \\
\text { Mobile Phase B: Methanol }\end{array}$} \\
\hline Flow Rate & $\begin{array}{l}\text { Time }(\min ) \\
0-20 \\
20-25 \\
25-30 \\
30-32 \\
32-40\end{array}$ & $\begin{array}{l}\text { Mobil Phase } \mathrm{B}(\% \mathrm{~V} / \mathrm{V}) \\
60 \text { isocratic } \\
60 \rightarrow 90 \\
90 \text { isocratic } \\
90 \rightarrow 60 \\
60 \text { isocratic stabilisation }\end{array}$ \\
\hline
\end{tabular}

\subsection{Method validation}

Method validation was performed according to International conference on harmonization (ICH) Q2(R1) Validation of analytical procedures: text and methodology guidelines [14].

\subsubsection{Product and placebo}

The products are manufactured according to the formulation given in Table 2. Placebo used in specificity study was formulated the same way except extract itself. For accuracy studies $80 \%$ and $120 \%$ extract containing formulations were also prepared with $16 \mathrm{mg}$ extract with $64 \mathrm{mg}$ lactose and $24 \mathrm{mg}$ extract with 56 mg lactose respectively.

Table 2. Unit formula of tablets.

\begin{tabular}{lc}
\hline Ingredient & Amount For One Tablet (mg) \\
Agnus-castus Dry Extract & 20 \\
Lactopress Anhydrous Fine Powder (Lactose) & 60 \\
Pharmacel 101 (Microcrystalline Cellulose) & 60 \\
Ligamed MF-2-V (Magnesium stearate) & 1 \\
HDK N20 Pharma (Hydrophilic Pyrogenic Silica) & 1 \\
Opadry 200 Green Cellulose & 3 \\
TOTAL & 145 \\
\hline
\end{tabular}

\subsubsection{Specificity}

Specificity is the ability to assess the analyte in the presence of components that may be expected to be present, such as impurities, degradation products, and matrix components. To assess the specificity with casticin; methanol as solvent, mobile phase, placebo, agnus-castus fruit dry extract reference substance (HRS) 
and the product itself were injected to the system according to the method described in material methods section. Table 3 shows the results of specificity test and chromatogram of the product could be seen in Figure 1.

Table 3. Results showing the retention times of penduletin and casticin. Casticin peak purity index measured by PDA spectrum and calculated as 0.999 .

\begin{tabular}{lccc}
\hline Sample & $\begin{array}{c}\text { Penduletin } \\
\text { Retention Time }\end{array}$ & $\begin{array}{c}\text { Casticin Retention } \\
\text { Time }\end{array}$ & Resolution \\
\hline Agnus-Castus Fruit Dry Extract HRS & 14.45 & 15.97 & 2.55 \\
Product & 14.43 & 15.96 & 2.55 \\
Methanol (Solvent) & - & - & - \\
Mobile Phase & - & - & - \\
Placebo & - & - & - \\
\hline
\end{tabular}

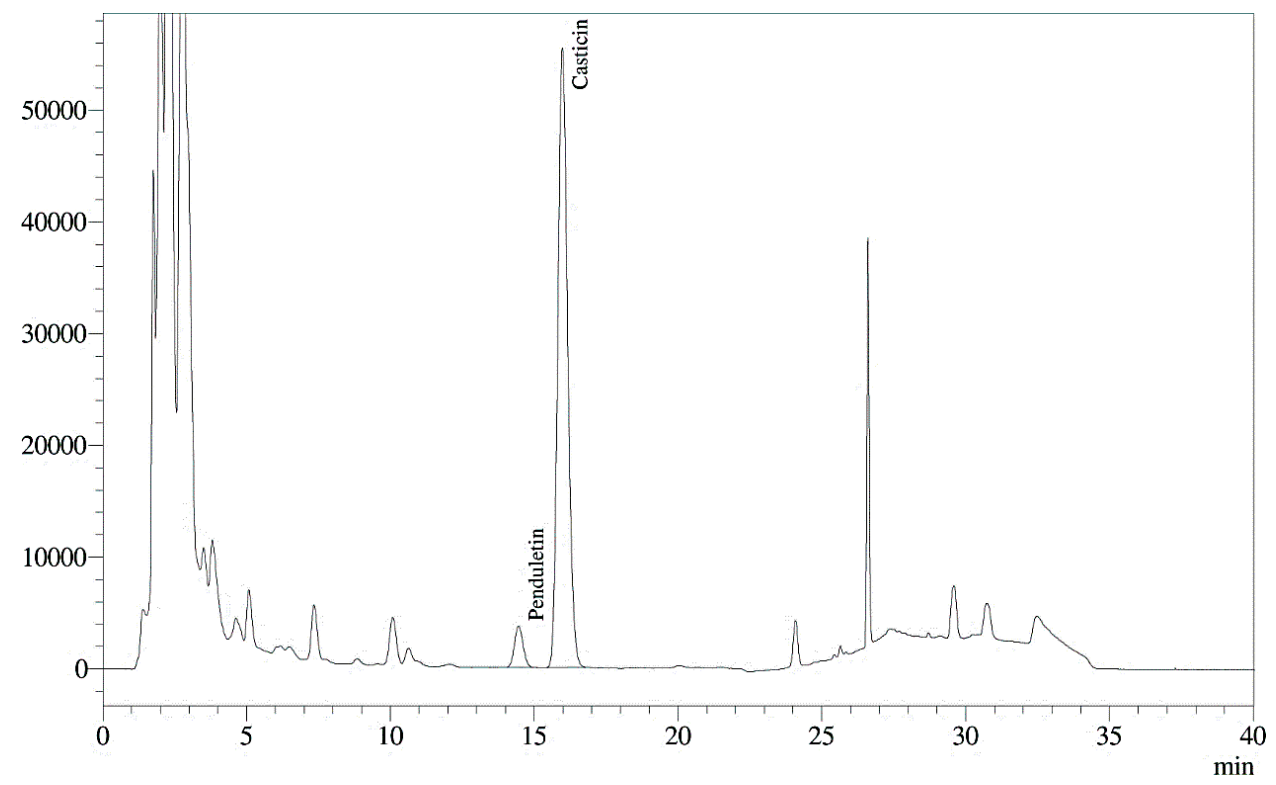

Figure 1. Chromatogram of tablets containing agnus-castus extract.

\subsubsection{System repeatability, system suitability, range and linearity}

To achieve system repeatability, system suitability and linearity; $50 \%, 80 \%, 100 \%, 120 \%$ and $150 \%$ concentration of agnus-castus fruit dry extract HRS was prepared according to the method described in material and methods section. 100\% concentration solution was injected six times and the others were injected three times to achieve linearity, system repeatability and system suitability. Table 4 illustrate the results for casticin peak areas while Figure 2 demonstrates the calibration curve for linearity test. Acceptance for the range test were based on the following; range of the method should be linear, accurate, and repeatable between the $80 \%$ and the $120 \%$ of the solution and the results compiles with the criteria.

\subsubsection{Accuracy}

The accuracy of method was determined by means of recovery data. For this purpose formulations which contain 16, 20 and $24 \mathrm{mg}$ extract were used to achieve $80 \%, 100 \%$ and $120 \%$ of the real concentrations respectively. Three sets of samples were analysed for each concentration and each sample tested for twice. The amount of agnus-castus extracts in the products were calculated according to the formula given below and Table 5 demonstrates the accuracy studies.

In the formula; A1: area of casticin in product, A2: area of casticin in HRS, m1: HRS in reference solution in miligrams, p1: Casticin percentage in HRS, p2: Casticin percentage in raw material (Casticin content should be quantified in raw material before use).

Agnus-castus extract in tablets $(\mathrm{mg})=\frac{\mathrm{A} 1 \times \mathrm{m} 1 \times \mathrm{p} 1}{\mathrm{~A} 2 \times 5 \times \mathrm{p} 2}$ 
Table 4. System repeatability, system suitability, range and linearity data. The calculated RSD\% was $\leq 2.0$ for system repeatability and the system suitability tests complies with the criteria.

\begin{tabular}{|c|c|c|c|}
\hline Concentration & $\begin{array}{c}\text { Casticin Peak } \\
\text { Area }\end{array}$ & $\begin{array}{c}\text { Average Casticin } \\
\text { Area }\end{array}$ & RSD (\%) \\
\hline \multirow{3}{*}{$50 \%$ (25 mg Agnus-castus dry extract HRS) } & 354757 & \multirow{3}{*}{355143} & \multirow{3}{*}{0.12} \\
\hline & 355602 & & \\
\hline & 355071 & & \\
\hline \multirow{3}{*}{ 80\% (40 mg Agnus-castus dry extract HRS) } & 570256 & \multirow{3}{*}{571955} & \multirow{3}{*}{0.25} \\
\hline & 572949 & & \\
\hline & 572659 & & \\
\hline \multirow{6}{*}{$100 \%$ (50 mg Agnus-castus dry extract HRS) } & 706102 & \multirow{6}{*}{707225} & \multirow{7}{*}{0.1} \\
\hline & 707625 & & \\
\hline & 707376 & & \\
\hline & 707806 & & \\
\hline & 706668 & & \\
\hline & 707775 & & \\
\hline \multirow{3}{*}{$120 \%$ (60 mg Agnus-castus dry extract HRS) } & 845769 & \multirow{3}{*}{845880} & \\
\hline & 846081 & & \multirow[t]{3}{*}{0.02} \\
\hline & 845790 & & \\
\hline \multirow{3}{*}{ 150\% (75 mg Agnus-castus dry extract HRS) } & 1069263 & \multirow{3}{*}{1069443} & \\
\hline & 1069443 & & \multirow[t]{2}{*}{0.01} \\
\hline & 1069624 & & \\
\hline
\end{tabular}

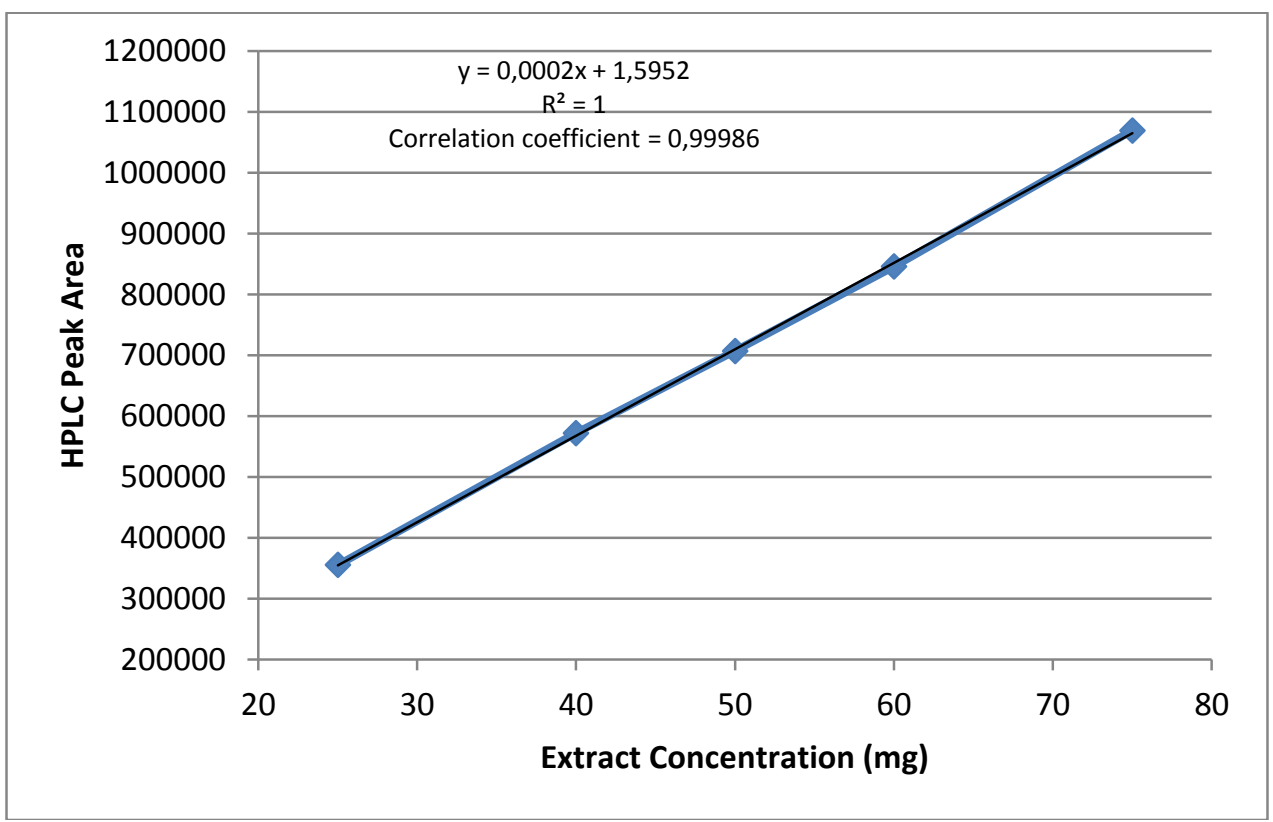

Figure 2. Calibration curve for casticin plotted between the correlation of extract concentration (mg) and HPLC peak area.

\subsubsection{Precision}

The precision of an analytical procedure is the degree of agreement among individual test results when the procedure is applied repeatedly to multiple samplings of a homogeneous sample. Precision of the method assessed in terms of repeatability, intermediate precision and reproducibility. Reproducibility refers to the use of the analytical procedure in different laboratories, as in a collaborative study. Intermediate precision (also known as ruggedness) expresses within-laboratory variation, as on different days, or with different analysts or equipment within the same laboratory. Repeatability refers to the use of the analytical procedure within a 
laboratory over a short period of time using the same analyst with the same equipment. Table 6 shows intermediate precision and repeatability data while Table 7 demonstrates the reproducibility of the method.

Table 5. Accuracy studies for tablets. 20 mg extract containing tablets were referred to as $100 \%$.

\begin{tabular}{|c|c|c|c|c|}
\hline $\begin{array}{l}\text { Sample } \\
\text { Concentration }\end{array}$ & $\begin{array}{l}\text { Agnus-castus } \\
\text { Extract in Tablets } \\
(\mathrm{mg})\end{array}$ & $\begin{array}{l}\text { Analysed Agnus- } \\
\text { castus Extract in } \\
\text { Tablets (mg) }\end{array}$ & RSD (\%) & Recovery \% \\
\hline \multirow{2}{*}{$80 \%$} & 16.0 & 15.87 & \multirow{6}{*}{0.86} & 99.19 \\
\hline & 16.0 & 15.85 & & 99.06 \\
\hline \multirow{2}{*}{$80 \%$} & 16.0 & 15.73 & & 98.31 \\
\hline & 16.0 & 15.79 & & 98.69 \\
\hline \multirow{2}{*}{$80 \%$} & 16.0 & 16.08 & & 100.50 \\
\hline & 16.0 & 16.03 & & 100.19 \\
\hline \multirow{2}{*}{$100 \%$} & 20.0 & 20.11 & \multirow{6}{*}{0.14} & 100.55 \\
\hline & 20.0 & 20.08 & & 100.40 \\
\hline \multirow{2}{*}{$100 \%$} & 20.0 & 20.06 & & 100.30 \\
\hline & 20.0 & 20.04 & & 100.20 \\
\hline \multirow{2}{*}{$100 \%$} & 20.0 & 20.09 & & 100.45 \\
\hline & 20.0 & 20.11 & & 100.55 \\
\hline \multirow{2}{*}{$120 \%$} & 24.0 & 23.95 & \multirow{6}{*}{0.24} & 99.79 \\
\hline & 24.0 & 23.97 & & 99.88 \\
\hline \multirow{2}{*}{$120 \%$} & 24.0 & 23.86 & & 99.42 \\
\hline & 24.0 & 23.91 & & 99.63 \\
\hline \multirow{2}{*}{$120 \%$} & 24.0 & 24.02 & & 100.08 \\
\hline & 24.0 & 23.98 & & 99.92 \\
\hline
\end{tabular}

Table 6. The assessment of repeatability and intermediate precision.

\begin{tabular}{lll}
\hline Agnus-castus Extract in the Product $\mathbf{( m g )}$ & Analyst-1 (mg) & Analyst-2 (mg) \\
\hline 20 & 20.03 & 20.08 \\
20 & 20.05 & 20.04 \\
20 & 19.97 & 20.06 \\
20 & 20.07 & 19.98 \\
20 & 19.98 & 19.96 \\
20 & 20.05 & 19.92 \\
\hline & Statistics \\
\hline Mean \pm SE & $20.03 \pm 0,017$ & $20 \pm 0.03$ \\
RSD $(\%)$ & 0.20 & 0.31 \\
\hline
\end{tabular}

Table 7. Data obtained from reproducibility study.

\begin{tabular}{ll}
\hline Agnus-castus Extract in the Product $\mathbf{( m g )}$ & Analyst-1 (mg) \\
\hline 20 & 19.96 \\
20 & 20.08 \\
20 & 20.06 \\
20 & 19.91 \\
20 & 19.95 \\
20 & 20.03 \\
\hline & Statistics \\
\hline Mean \pm SE & $19.99 \pm 0.03$ \\
RSD (\%) & 0.34 \\
\hline
\end{tabular}




\subsubsection{Limit of detection and limit quantification ( $L O D$ and $L O Q$ )}

Analytical procedures for quantitation of major components of bulk drug substances or active ingredients (including preservatives) in finished pharmaceutical products are classified as category 1. United States Pharmacopoeia states that LOD and LOQ test data elements are not required for this category [15].

\subsubsection{Robustness}

The robustness of an analytical procedure is the measure of method capacity to remain stable with relatively small amount of changes in method parameters [15]. Robustness test were evaluated by increasing the flow rate at $10 \%$ and increasing the temperature of the column for $5^{\circ} \mathrm{C}$. Average result of $100 \%$ concentration for accuracy test data were used as the unchanged method data. Table 8 shows the data of robustness tests including difference of the results as percentage.

Table 8. The results illustrating robustness test data.

\begin{tabular}{lll}
\hline Normal Method & Flow Increased Method & Difference (\%) \\
\hline $20.08 \mathrm{mg}$ & $20.02 \mathrm{mg}$ & 0.29 \\
\hline Normal Method & Temperature Increased Method & Difference (\%) \\
\hline $20.08 \mathrm{mg}$ & $19.96 \mathrm{mg}$ & 0.59 \\
\hline
\end{tabular}

\subsubsection{Solution stability}

Test solutions used in accuracy tests were kept in $4{ }^{\circ} \mathrm{C}$ and $25^{\circ} \mathrm{C}$ in the dark for 48 hours and analysed again to achieve solution stability. Solution remained stable in the solution as seen in Table 9.

Table 9. The results of solution stability data.

\begin{tabular}{lll}
\hline $\begin{array}{l}\text { Fresh Solution Casticin Peak } \\
\text { Area }\end{array}$ & $\begin{array}{l}\mathbf{4 8} \text { hours in } \mathbf{4}^{\circ} \mathbf{C} \text { Casticin Peak } \\
\text { Area }\end{array}$ & $\begin{array}{l}\mathbf{4 8} \text { hours in } \mathbf{2 5}{ }^{\circ} \mathbf{C} \text { Casticin Peak } \\
\text { Area }\end{array}$ \\
\hline 706102 & 707185 & 707456 \\
\hline 707625 & 707248 & 707247 \\
\hline 707376 & 706982 & 707325 \\
\hline 707806 & 707882 & 707452 \\
\hline 706668 & 706924 & 707016 \\
\hline 707775 & 707123 & 707043 \\
\hline
\end{tabular}

\subsection{Formulation stability}

Accelerated and long term stability tests were carried out to confirm the stability of the herbal product in primary packaging material according to ICH Q1A(R2); Stability testing of new drug substances and products guidelines [16]. Accelerated stability conditions were as follows; $40 \pm 2^{\circ} \mathrm{C}, 75 \% \pm 5 \%$ R.H meanwhile long term stability conditions were $25 \pm 2{ }^{\circ} \mathrm{C}, 60 \% \pm 5 \%$ R.H. Table 10 shows the accelerated stability test results. Long term stability control test periods were $1,3,6,9,12,18$, 24th months and the results were in the limits.

Table 10. Accelerated stability data.

\begin{tabular}{|c|c|c|c|c|}
\hline Product Specifications & & Time Periods & & \\
\hline Tests & Limits & 1. month & 3. month & 6. month \\
\hline Average Tablet Weight & $\begin{array}{l}145 \mathrm{mg} / \text { tablet } \pm 7.5 \% \\
(134.13 \mathrm{mg}-155.90 \mathrm{mg})\end{array}$ & $143.57 \mathrm{mg}$ & $145.36 \mathrm{mg}$ & $144.92 \mathrm{mg}$ \\
\hline Disintegration & Maximum 30 minutes & Confirms & Confirms & Confirms \\
\hline Moisture (Karl Fischer) & Maximum 3\% & $2.27 \%$ & $2.38 \%$ & $1.97 \%$ \\
\hline $\begin{array}{l}\text { Assay (Agnus-castus fruit } \\
\text { extract in mg) }\end{array}$ & $20 \pm 2 \mathrm{mg}$ & $20.08 \mathrm{mg}$ & $20.13 \mathrm{mg}$ & $20.05 \mathrm{mg}$ \\
\hline
\end{tabular}




\subsection{Physical properties}

Disintegration tests of tablets were performed with a PTZ-S single basket tablet disintegrator (Pharma Test Apparatebau AG/Germany). All the tablets were disintegrated less than 20 minutes (17.8 min. average). As an in-process control parameter, friability test of tablets before coating were performed with PTF 100 single drum friability test instrument (Pharma Test Apparatebau AG/Germany) and not more than $0.6 \%$ of tablet weight was lost. A dissolution test was not reported in this study because disintegration is shown to be more discriminating than dissolution as stated by European Medicine Agency [17].

\section{CONCLUSION}

Researches show that products containing Vitex agnus-castus L. fruit extract are as effective as the prescription drugs. However there are only a few registered herbal medicinal products on the market and the quality of dietary supplements are questionable. The following study demonstrates a stable oral formulation and a fully validated analytical method to comply the related parts of CTD and could be used while registering agnus-castus as traditional herbal medicinal product.

\section{MATERIALS AND METHODS}

Methanol and orthophosphoric acid were purchased from Merck (Darmstadt, Germany). Reference substances of agnus-castus fruit dry extract HRS was purchased from EDQM (Strasburg, France). EP grade agnus-castus fruit dry extract with a casticin content of $0.45 \%$ by weight was purchased from Naturex (Avignon, France). Naturex extract was quantified with EDQM reference substances before using as raw material to produce the dosage forms. The methods were developed and validated using a Shimadzu UFLC Prominence (Kyoto, Japan) system coupled with a PDA detector. Column was purchased from GLSciences (Japan). Analytical method parameters are listed in Table 1. Hitachi Aquacounter AQV 300 (Tokyo, Japan) was used to quantify water amount in the formulations. Lactopress anhydrous fine powder with a $\mathrm{d} 90$ value of 70 micron and Pharmacel 101 with a d90 value of 120 micron were purchased from DFE Pharma (Goch, Germany). Opadry 200 was purchased from local distributor of Colorcon (Harleysville, PA, USA). Magnesium stearate (Ligamed MF-2-V, Peter Greven, Bad Muenstereifel, Germany) and colloidal silica (HDK N20, Wacker Chemie AG, München, Germany) were pharmaceutical grade and purchased from the related brands.

\subsection{Formulating and producing the dosage forms}

Agnus-castus dry extract and the rest of excipients were mixed in a cubic mixer for 30 minutes according to the unit formula given in Table 2. After mixing the ingredients, the tablets were pressed with a Karnavati Mini Press I (Gujarat, India) small-scale compression machine. Placebo was prepared same way without the extract itself. $80 \%$ and $120 \%$ extract containing formulations were prepared with $16 \mathrm{mg}$ extract-64 mg lactose and $24 \mathrm{mg}$ extract-56 mg lactose respectively for accuracy studies in method validation. Prism LABOcoata- 12 (Gujarat, India) tablet coating machine was used for film coating with 3\% solution of Opadry 200. Finally 30 tablets were packaged with PVC-aluminium blisters.

\subsection{Assay method}

To prepare reference solution; $100 \mathrm{mg}$ Agnus-castus fruit dry extract HRS was introduced into a $50 \mathrm{~mL}$ volumetric flask. Flask was filled with $40 \mathrm{~mL}$ of methanol and sonicated for 15 minutes. After cooling to the room temperature filled up to the volume with methanol, filtered through a $50 \mu \mathrm{m}$ PTFE membrane filter into an analytical vial and $20 \mu \mathrm{L}$ of the solution was subjected to injection.

Sample solution was prepared same way except five pounded tablets were introduced to the volumetric flask.

To achieve the system suitability, resolution between penduletin and casticin should be $\geq 2$ and RSD $\%$ of casticin peak areas should be $\leq 2$ for two sequential reference solution injection. The amount of agnus-castus extract in dosage forms could be calculated with the formula given in 2.2.4 Accuracy section.

\subsection{Stability studies}

Accelerated and long term stability tests for products in primary packaging material were performed in a Binder KBF 115 (Tuttlingen, Germany) stability chamber. The conditions and sampling periods were described in 2.3 Formulation Stability section. 
Author contributions: Concept - İ.D., M.K.; Design - İ.D., M.K.; Supervision - M.K.; Materials - İ.D., M.K.; Data Collection and/or Processing - İ.D., M.K.; Analysis and/or Interpretation - İ.D., M.K.; Literature Search - İ.D., M.K.; Writing - İ.D., M.K.; Critical Reviews - İ.D., M.K.

Conflict of interest statement: The authors declared no conflict of interest.

\section{REFERENCES}

[1] International Conference on Harmonization (ICH), ICH M4; Organisation of the common technical document for the registration of pharmaceuticals for human use, Geneva, Switzerland, 2016.

[2] International Conference on Harmonization (ICH), ICH M4Q(R1); Organisation of the common technical document for the registration of pharmaceuticals for human use: Quality - M4Q(R1), Geneva, Switzerland, 2002.

[3] Milewicz A, Geidel E, Sworen H, Sienkiewicz K, Jedrzejak J, Teucher T, Schmitz H. Vitex agnus-castus extract in the treatment of luteal phase defects due to latent hyperprolactinaemia. Results of a randomized placebo-controlled double blind study. Arzneimittel-Forschung. 1993; 43(7): 752-756.

[4] Wutke W, Jarry H, Christoffel V, Spengler B, Seidlova-Wuttke D. Chaste tree (Vitex agnus-castus) - Pharmacology and clinical indications. Phytomedicine. 2003; 10(4): 348-357. [CrossRef]

[5] Odenthal KP. Vitex agnus-castus L. - Traditional drug and actual indications. Phytother Res; 1998; 12(S1): 160-161.

[6] He Z, Chen R, Zhou Y, Geng L, Zhang Z, Chen S, Yao Y, Lu J, Lin S. Treatment for premenstrual syndrome with Vitex agnus castus: A prospective, randomized, multi-center placebo controlled study in China. Maturitas. 2009; 63(1): 99-103. [CrossRef]

[7] European Union herbal monograph on Vitex agnus-castus L., fructus. EMA/HMPC/606742/2017. European Medicines Agency, London, 2018.

[8] Assessment report on Vitex agnus-castus L., fructus. EMA/HMPC/606741/2018. European Medicines Agency, London, 2018.

[9] European Pharmacopoeia, Ph. Eur. 9th ed. Agnus castus fruit dry extract. Council of Europe. 01/2015: 2309.

[10] Lee H, Jung KH, Park S, Choi W, Bae H. Casticin, an active compound isolated from Vitex Fructus, ameliorates the cigarette smoke-induced acute lung inflammatory response in a murine model. Int Immunopharmacol. 2015; 28: 1097-1101. [CrossRef]

[11] Elford BC, Roberts MF, Phillipson JD, Wilson RJ. Potentiation of the antimalarial activity of qinghaosu by methoxylated flavones. Trans R Soc Trop Med Hyg. 1987; 81: 434-436.

[12] Choudhary MI, Jalil S, Nawaz SA, Khan KM, Tareen RB. Antiinflammatory and lipoxygenase inhibitory compounds from Vitex agnus-castus. Phytother Res. 2009; 23: 1336-1339. [CrossRef]

[13] Chan EWC, Wong SK, Chan HT (2018) Casticin from Vitex species: a short review on its anticancer and antiinflammatory properties. J Integr Med. 2018; 16: 147-152. [CrossRef]

[14] International Conference on Harmonization (ICH), ICH Q2 (R1); Validation of Analytical Procedures: Text and methodology. International Conference on Harmonization, Geneva, Switzerland, 2005.

[15] General Information / (1225) Validation of Compendial Procedures. United States Pharmacopeia and National Formulary (USP 41-NF 36). Rockville, MD: United States Pharmacopeial Convention; 2016.

[16] International Conference on Harmonization (ICH), ICH Q1A(R2); Stability Testing of New Drug Substances and Products. International Conference on Harmonization, Geneva, Switzerland, 2003.

[17] Guideline on specifications: test procedures and acceptance criteria for herbal substances, herbal preparations and herbal medicinal products / traditional herbal medicinal products. EMA/CPMP/QWP/2820/00 Rev. 2.European Medicines Agency, London, 2011.

This is an open access article which is publicly available on our journal's website under Institutional Repository at http://dspace.marmara.edu.tr. 